\title{
Advokasi UU ITE:Peningkatan Kewaspadaan Guru Terhadap Serangan Cyberbullying Antar Peserta Didik Di Gugus II Harjuno (Pengabdian Masyarakat pada Gugus II Harjuno Surakarta)
}

\author{
Faulinda Ely Nastiti ${ }^{1}$, Rina Arum Prastyanti ${ }^{2}$, Agustina Srirahayu ${ }^{3}$ \\ Universitas Duta Bangsa \\ 1,2,3 Jl. Bhayangkara no 55, Tipes, Serengan Surakarta \\ Email : ${ }^{1}$ faulinda.en@gmail.com, ${ }^{2}$ rina_arum@udb.ac.id
}

\begin{abstract}
Abstrak
Undang Undang Informasi dan Transaksi Elektronik (atau biasa disebut dengan UU ITE) adalah undang undang yang mengatur mengenai teknologi informasi secara umum. Undang undang ini penting untuk dipahami bagi siapapun. Perkembangan teknologi melahirkan bentukbentuk perbuatan hukum baru seperti halnya cyberbullying. Cyberbullying dan pelanggaran UU ITE justru lebih banyak terjadi pada usia anak-anak hingga remaja. Kebebasan penggunakan internet serta kebebasan berpendapat yang salah, menyebabkan utama anak-anak dan remaja ini tanpa sadar telah melanggar hukum. Hal ini terjadi karena kurangnya pengetahuan tentang UU ITE. Melalui kegiatan pengabdian kepada masyarakat ini diharapkan, melalui para guru anak-anak serta orangtua mendapatkan sosialisasi dan pendampingan etika pemanfaatan intenet dengan bijak.
\end{abstract}

Kata kunci:UU ITE, cyberbullying, anak-anak, remaja, guru.

\section{PENDAHUluan}

Salah satu upaya mewujudkan suatu Cyberbullying adalah perilaku yang dilakukan individu atau kelompok ditujukan kepada individu melalui berbagai media. Perlakuan cyberbullying tidak dimaksud untuk melukai seseorang secara langsung, namun perlakuan ini sering kali dimaksudkan untuk menyakiti seseorang secara psikis sehingga orang tersebut menjadi malu dan tersudutkan akan membuat seseorang itu menjadi susah untuk bergaul dengan lingkungan sekitar (Sakban, Sahrul, Kasmawati, \& Tahir, 2018). Perilaku seperti itu seharusnya tidak di lakukan.

Perilaku bullying yang terjadi di lingkungan sekolah sering kali diberikan di berbagai media masa seperti televisi dan surat kabar. Banyak juga rekaman video perilaku bullying di lingkungan sekolah yang beredar di media sosial seperti Facebook, Instagram, dan Youtube. Saat ini perilaku bullying sudah merambah di kolom komentar sosial media seperti Instagram yang sudah menjamur. Perilaku bullying menyerang pengguna sosial media yang menyinggung tentang fisik dan psikis seseorang, fenomena tersebut sangat memprihatinkan dan menimbulkan kecaman dari berbagai pihak (Sakban et al., 2018).

Berdasarkan data yang dilansir IDN Times jumlah anak yang menjadi korban bullying media sosial ada 34 kasus di tahun 2016, kemudian meningkat menjadi 55 kasus di tahun 2017. Jumlah cyberbullying bertambah menjadi 109 kasus di sepanjang tahun 2018, sedangkan kasus sebagai pelaku cyberbullying lebih besar. Di tahun 2016, ada 56 anak jadi pelaku cyberbullying, jumlah ini naik pada tahun 2017 menjadi kasus 73 kasus dan meningkat pada tahun 2018 menjadi 117 kasus (Akbari \& Falopenia, 2017). Bullying bagaikan fenomena gunung es faktanya dilapangan jumlah kasus perundungan anak di media sosial yang tidak melaporkan ke KPAI lebih banyak. Berdasarkan laporan tahunan KPAI, kasus bullying di media sosial muncul sejak 2016, hal ini dipicu kemajuan teknologi dan media sosial serta kemudahan anak untuk mengakses internet.

Begitu banyaknya layanan yang ditawarkan oleh jaringan internet, bahkan banyak penggunannya yg tidak bijak dalam menggunakan internet jika sudah berhadapan dengan perangkat mereka, baik laptop, computer, maupun HP. Ini jelas menjadi suatu masalah, apalagi belakangan ini banyak layanan seperti media sosial, misalnya Instagram, Twitter, Facebook, sharing status Whats App dan lain-lain. kemudahan akses internet yang sejatinya digunakan untuk menunjang pendidikan dan segala sesuatu 
yang berbau positif justru disalahgunakan. Banyak sekali kasus kriminalitas akibat dari jaringan pertemanan dunia maya yang justru jaringan tersebut sangat digemari oleh remaja, berikut adalah faktor terjadinya penyalah gunaan internet: 1) kurangnya pengawasan dari orangtua, 2) Peran guru di sekolah masih kurang., 3) Pergaulan yang salah, 4) Adanya godaan dari dalam hati yang tidak dapat dicegah untuk membuka/melakukan share data dan status negative.

\section{METODE PENELITIAN}

Pelaksanaan Pengabdian Masyarakat ini di bagi menjadi 3 (tiga) kegiatan utama yaitu 1) Persiapan

Pada tahap ini, tim pengabdian melakukan diskusi dengan Dra. Sri Wahyuni, MM selaku Pengawas Sekolah pada Dinas Pendidikan Surakarta. Diskusi ini dilakukan untuk menentukan gugus pendidikan mana yang paling membutuhkan pembinaan ITE.

2) Persiapan Modul

a) Tim membuat modul berisi rangkuman dari UU ITE agar mudah dipahami oleh guru.

b) Selain itu tim pengabdian masyarakat juga menyiapkan slide presentasi berupa bahaya cyberbullying pada kalangan anak-anak.

3) Pendampingan

Pendampingan yang dilakukan dengan pendekatan Advokasi. Kegiatan advokasi dilakukan dengan cara sosialisasi pentinganya kesadaran guru dalam memahami UU ITE, dan pendampingan terhadap guru dalam memberantas cyberbullying. Keberhasilan yang diharapkan adalah peningkatan kesadaran UU ITE, dan hadirnya kebijakan etika pemanfaatan internet dan media pembelajaran digital di lingkungan Sekolah Dasar Wilayah Gugus II Harjuno Serengan Surakarta, untuk menghidari adanya cyberbullying antar siswa.

\section{HASIL DAN PEMBAHASAN \\ a. Kegiatan Koordinasi Sekaligus Survey Sekolah Pelaksanaan Kegiatan Pengabdian}

Kegiatan ini merupakan koordinasi awal dengan pengawas sekolah yaitu Dra. Sri Wahyuni, MM yang merupakan pengawas di wilayah Gugus II Kecamatan Serengan kota Surakarta. Hasil koordinasi dengan pengawas sekolah menyatakan bahwa Pemahaman guru terhadap pemanfataan Internet yang sesuai dengan Undang-Undang SISDIKNAS dan UU ITE masih sangat kurang. Guru kesulitas dalam mengembangan pembelajarn berbasis IT karena keterbatasan guru dalam mengikuti perkembangan IT dalam pembelajaran IPA Selama ini, guru IPA menggunakan metode pembelajaran yang konvensional dalam memberikan pemahaman siswa terhadap objekobjek IPA. Hasil koordinasi dengan pimpinan pengawas sekolah, disepakati kegiatan dilaksanakandi Aula Fakultas Ilmu Komputer Universitas Duta Bangsa pada Tanggal 18 Januari 2019 dengan fasilitas ruang aula, sound system dan LCD.

\section{b. Edukasi UU ITE}

Pelaksanaan kegiatan diawali oleh Pemateri I Dr Rina Arum Prastyanti yang menyampaikan Edukasi UU ITE untuk pembelajaran. Pada kesempatan ini pemateri memberi umpan balik kepada peserta workshop tentang pengetahuan mereka terhadap UU ITE dan pembelajaran menggunakan internet serta implikasinya kepada peserta didik. Setelah itu dilanjutkan dengan penyampaian materi dan tanya jawab.

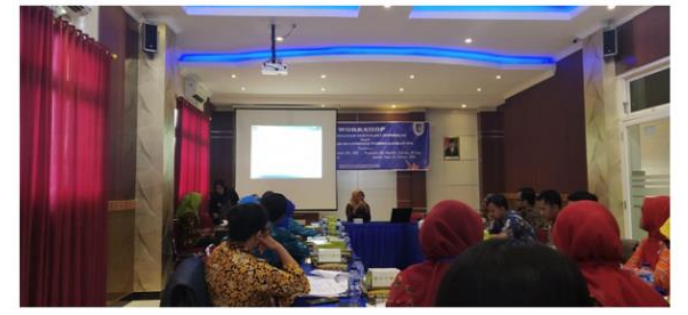

Gambar 1 Penyampaian Materi Edukasi UU ITE

\section{c. Edukasi Cyberbullying}

Pelaksanaan kegiatan edukasi cyberbullying dilakukan oleh Faulinda Ely Nastiti dan Agustina Srirahayu. Pada kegiatan edukasi ini tim memaparkan fenomena internet dan kasus-kasus serangan cyberbullying yang berdampak pada psikologi anak yang terserang.

\section{1) Internet}

Pemanfaatan Internet di Indonesia berkembang sangat cepat, bagaimana tidak? Orang tua tanpa sadar telah mengenalkan internet semenjak anak mereka balita. Pengenalan internet melalui Youtube dengan alasan agar bayi teralih fokusnya, malah justru tanpa sadar merusak pola asuh yang benar. 
Pada pengabdian ini tim memaparkan data sebagai berikut:

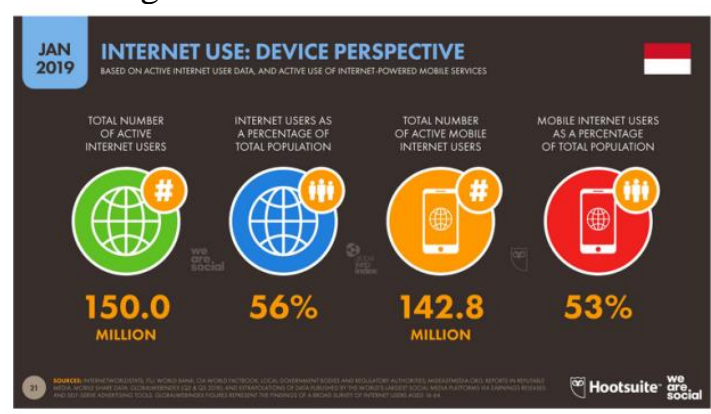

Gambar 2 Populasi Pengunaan Internet (Websindo, 2019)

Pada gambar 2 bisa dilihat bahwa populasi pengguna internet sejumlah 150 juta orang. Hal ini berbanding lurus dengan populasi penggunaan social media yang menekati 150 juta pengguna aktif social media (Websindo,2019). Hampir 72 juta pengguna social media adalah kalangan usia anak-anak hingga remeja, gambar 3 .

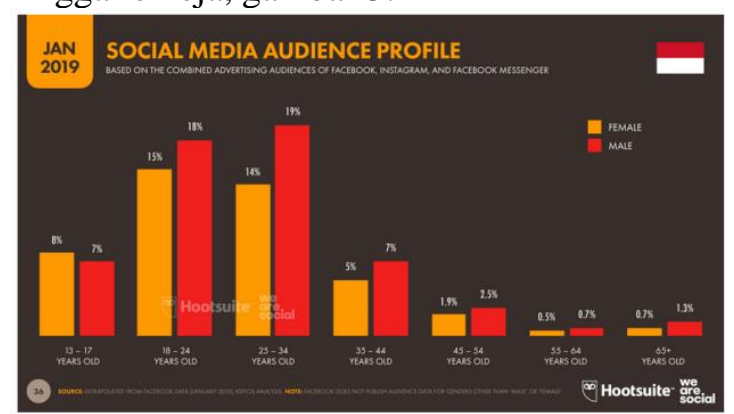

Gambar 3 Populasi Pengunaan Internet (Websindo, 2019)

Usia anak-anak dan remaja merupakan usia yang rentan terhadap informasi. Dimana semua informasi yang didapat akan mempengaruhi prilaku keseharian.

Keseharian anak-anak dan remaja waktunya lebih di dunia sekolah, oleh sebab itulah kenapa guru perlu berpartisipasi dalam memonitor sikap dan pengaruh internet pada peserta didik.

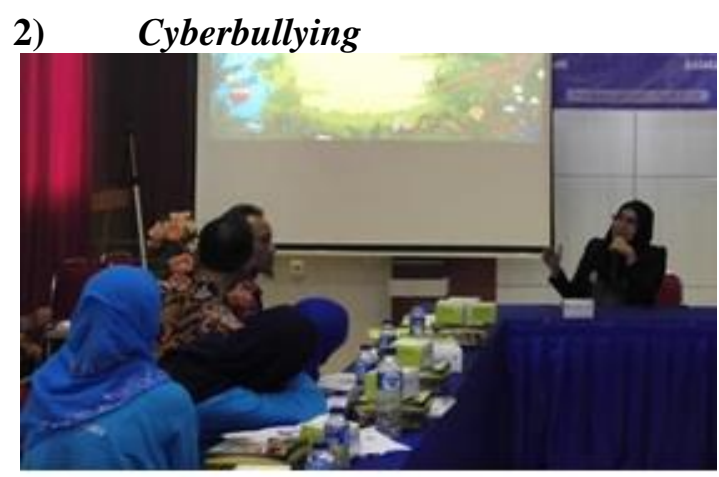

Gambar 2 Penyampaian Materi Proses Cyberbullying

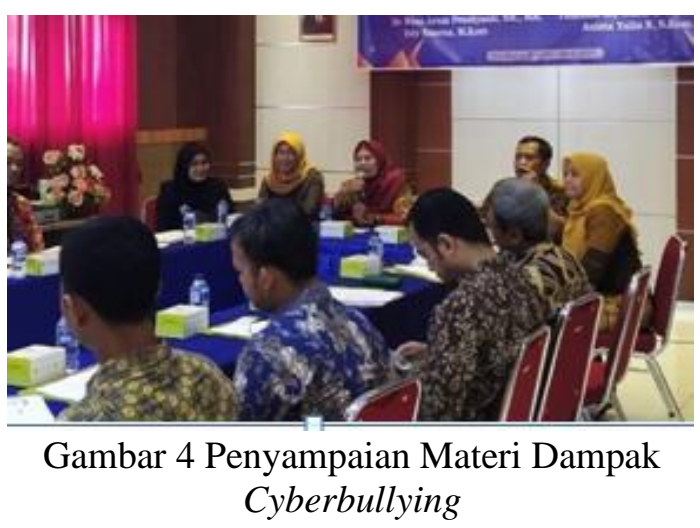

Bentuk tindakan bullying yang terjadi di sosial media berdampak buruk bagi korban. Korban bullying akan mengalami depresi, marah, tersinggung, bahkan sampai bunuh diri dalam kasus bullying yang berat. Meskipun orang tua dan sekolah sudah mendorong ke lingkungan online yang aman, akan tetapi masih sedikit hukumjalan untuk mencegah cyberbullying. Pengguna internet perlu diberi informasi tentang etika dalam penggunaan sosial media (Bara, 2014).

Berdasarkan kasus anak dari artis Uya Kuya yang dibuli di media sosial Instagram karena persoalan kecil yaitu tiket konser BTS.

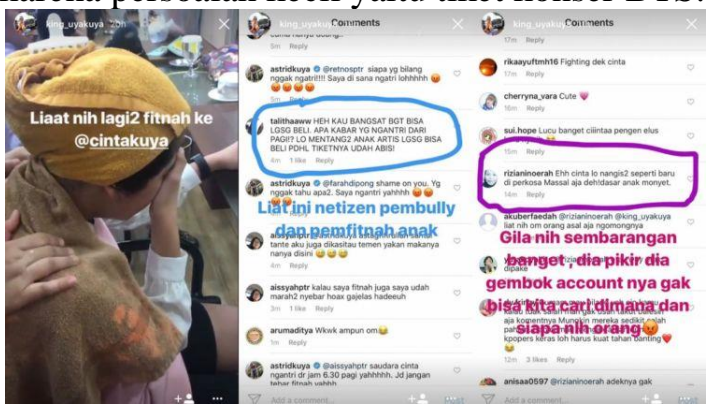

Gambar 5 Contoh Cyberbullying dan Tekanan Yang Diterima Korban 


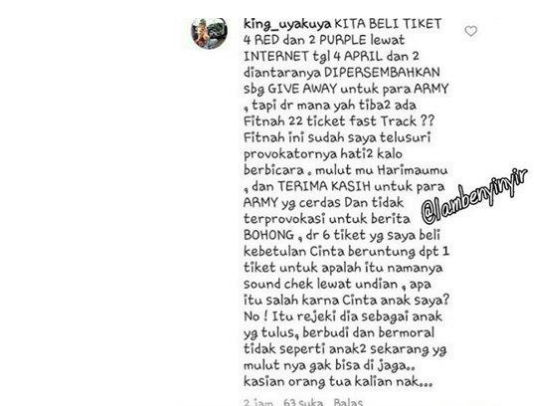

Gambar 6 Contoh Dampak Cyberbullying bagi Orangtua

Dampak yang dialami cinta kuya atas bullying depresi ringan yang berakibat jatuh sakit dan takut untuk berangkat ke sekolah selama 2 (dua) hari.

\section{d. Refleksi Kegiatan Edukasi Internet dan Cyberbullying}

Selama proses pelatihan, tim pelaksana kegiatan pengabdian melakukan pemantauan kepada peserta pelatihan sekaligus melakukan wawancara terhadap materi, metode dan instruktur dalam kegiatan ini. Secara umum guru mengatakan pelatihan ini sangat baik dan materi yang diberikan merupakan materi yang sangat dibutuhkan olek guru dengan instrukturnya sangat berkompoten.

\section{e. Refleksi Kegiatan Pendampingan Eika Pemanfaatan Internet}

Setelah diadakan edukasi kepada guru, tim peneliti melakukan pendampingan implementasi etika pemanfaatan internet dan media pembelajaran digital di lingkungan Sekolah Dasar Wilayah Gugus II Harjuno Serengan Surakarta, untuk menghidari adanya cyberbullying antar siswa.

Etika berinternet maksudnya perbuatan seseorang untuk menyampaikan pesan, menyebarkan pesan dan informasi baik untuk individu maupun kelompok melalui alat teknologi komunikasi. Dengan adanya teknologi komukasi, dapat memberikan nilai negatef dan positif bagi penggunanya (Waliyanti et al., 2018).

Sekolah melaksanakan kegiatan sosialisasi dalam bentuk penyuluhan secara dini kepada siswa dan orangtua tentang bahaya cyberbullying. Tidakan ini selaras dengan penelitian Sakban yang menyatakan " Guru pengurus kelas menanamkan sikap anti bullying" (Sakban et al., 2018). Kegiatan penyuluhan dilakukan dengan cara memberikan pelatihan kepada orangtua untuk membina dan memantau prilaku intenet anak mereka dirumah.

Diperlukan kebijakan dan ketegasan, serta peran langsung orang tua dalam memberikan kebebasan penggunaan internet dan media sosial. Beberapa tindakan yang dilakukan orang tua untuk pencegahan tindakan cyberbullying yaitu :

1) Memberikan ilmu agama lebih banyak.

2) Memberikan batasan waktu penggunaan smartphone pada anak.

3) Melihat dan mengenal teman-teman anaknya.

4) Memiliki akun sosial media untuk memantau anak.

5) Memiliki sikap kritis terhadap akun-akun yang melakukan tindakan seperti cyberbullying, penghinaan, dll

6) Melarang anak menggunakan sosial media jika belum cukup umur.

Peran orang tua sangat berpengaruh untuk mengontrol anak dalam menggunakan internet dan sosial media. Sesering mungkin orang tua mengecek perkembangan akun anaknya, ini dilakukan untuk menghindari adanya postingan yang mengandung unsure pencemaran nama baik, pelecehan, kekerasan (Satalina, 2014). Hal tersebut yang dapat membuat anak menjadi terpengaruh dan disaat itulah orang tua perlu memberikan pengertian dan ketegasan kepada anak.

\section{KESIMPULAN}

Kegiatan pengabdian Masyarakat sudah dilakukan berupa pendampingan dan edukasi UU ITE dan cyberbullying. Berdasarkan hasil diskusi dengan pengawas sekolah dan guruguru peserta pendampingan, mulai dari awal koordinasi dan selama pelaksanaan pengabdian, mereka sangat antusias. Terbukti setelah kegiatan edukasi dilaksanakan, para guru melakukan sosialisasi kepada murid dan orangtua siswa.

Pencegahan tindakan cyberbullying dapat dilakukan dengan kegiatan sosialisasi tentang penyuluhan bahaya dampak bullying dan bagaimana pencegahannya. Terlebih lagi peran orang tua yang sangat membantu pencegahan perilaku bullying sejak usia dini.

\section{UCAPAN TERIMAKASIH}

Terimakasih kepada Nu'rul Nur Pertiwi, Dandi Wicaksono, dan tim mahasiswa event organizer UDB, yang telah 
membantu tercapainya pengabdian hingga publikasi ini

\section{REFERENSI}

Akbari, T. T., \& Falopenia, A. C. (2017). Personal Image Generasi Millennial Korban Cyberbullying Pada Akun Instagram dan Ask Fm Di Jakarta Taufan. Prosiding Konferensi Nasional Komunikasi, 01(01), 657-667. Retrieved from http://pknk.org/index.php/PKNK/article/ view/47/52

Bara, M. (2014). Studi Deskriptif Perilaku Bullying pada Remaja. Jurnal Ilmiah Mahasiswa Universitas Surabaya, 3(1), $1-17$.

Damayanti, R. (2017). penggunaan bahasa alay pada bullying anak di media sosial. Jurnal Autentik, 1(2), 1-11.

Sakban, A., Sahrul, Kasmawati, A., \& Tahir, H. (2018). Tindakan Bullying di Media Sosial dan Pencegahannya. JISIP, 2(3), 205-214.

Satalina, D. (2014). Kecenderungan Perilaku Cyberbullying Ditinjau Dari Tipe Kepribadian Ekstrovert Dan Introvert. ISSN, 3(2), 1-46. https://doi.org/http://dx.doi.org/110.2104 3/equilibrium.v3i2.1268

Waliyanti, E., Kamilah, F., Fitriansyah, R. R., Studi, P., Keperawatan, I., \& Yogyakarta, U. M. (2018). Fenomena Perilaku Bullying pada Remaja di Yogyakarta. Jurnal Ilmiah Keperawatan Indonesia, 2(1), 50-64.

Websindo.

2019.

https://websindo.com/indonesia-digital-

2019-media-sosial/ diakses tanggal $7 / 7 / 2019$ 